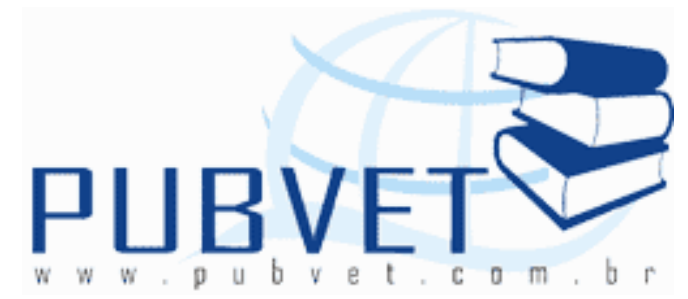

PUBVET, Publicações em Medicina Veterinária e Zootecnia.

\title{
Diagnóstico da leishmaniose visceral canina: uma revisão
}

Camila de Aguiar Lima ${ }^{1}$, Karine Raquel Teixeira ${ }^{2}$, João Paulo Fernandes Ferreira Moreira $^{3}$, Kelisson Ricardo Teixeira ${ }^{4}$

${ }^{1}$ Médica Veterinária, Mestranda pela Universidade Federal de Minas Gerais (UFMG).

${ }^{2}$ Biomédica, Universidade José do Rosário Vellano (UNIFENAS).

${ }^{3}$ Graduando em Medicina Veterinária pela Pontifícia Universidade Católica de Minas Gerais (PUC Minas).

${ }^{4}$ Químico, Mestrando pela Universidade Federal de Ouro Preto (UFOP).

\section{Resumo}

A leishmaniose visceral é uma zoonose grave e letal, que tem acometido milhares de cães e pessoas em nosso país. A doença possui difícil diagnóstico devido a vários fatores, como a inespecificidade de sinais clínicos e a ausência de um teste laboratorial que seja $100 \%$ sensível e específico. Atualmente, encontram-se disponíveis métodos sorológicos, parasitológicos, imunológicos e moleculares. Cada um destes métodos possui vantagens e desvantagens que devem ser criteriosamente avaliadas pelos médicos veterinários, a fim de serem utilizados da forma mais adequada e levarem a um correto diagnóstico, salvamento de vidas e sucesso no combate à doença. 
LIMA, C.A. et al. Diagnóstico da leishmaniose visceral canina: uma revisão. PUBVET, Londrina, V. 7, N. 25, Ed. 248, Art. 1641, Suplemento 1, 2013.

\title{
Diagnosis of canine visceral leishmaniasis: a review
}

\begin{abstract}
Visceral leishmaniasis is a zoonosis severe and lethal, which has affected thousands of dogs and people in our country. The disease has a difficult diagnose due to various factors, such as the nonspecific of clinical signs and the absence of a laboratory test that is $100 \%$ sensitive and specific. Currently, there are methods serological, parasitological, immunological and molecular. Each of these methods has advantages and disadvantages that should be carefully evaluated by veterinarians, in order to be used in the most appropriate form and lead to a correct diagnosis, rescue of lives and successfully combat the disease
\end{abstract}

\section{INTRODUÇÃO}

Difundida em quase todo o mundo, as Leishmanioses não são uma doença única, mas um conjunto de síndromes complexas e multifacetadas causadas por diversas espécies do gênero Leishmania. Nas Américas, a Leishmania chagasi é a espécie incriminada como agente causador da Leishmaniose Visceral Canina (LVC), sendo transmitida através da picada de fêmeas do inseto vetor infectado. No Brasil, a Lutzomyia longipalpis é considerada a principal espécie transmissora da doença ${ }^{13}$.

Além dos cães, os seres humanos também são acometidos, o que faz com que a leishmaniose visceral (LV) tenha grande impacto na saúde pública. Estima-se que cerca de milhões de pessoas sofram com a doença. Como pode ser transmitida dos animais ao homem, a Leishmaniose é classificada como zoonose ${ }^{13}$.

Um ponto importante a ser ressaltado é o de que não existem sinais clínicos específicos da LVC, uma vez que praticamente todos os sintomas podem corresponder também a outros diagnósticos. Dessa forma, o diagnóstico 
LIMA, C.A. et al. Diagnóstico da leishmaniose visceral canina: uma revisão. PUBVET, Londrina, V. 7, N. 25, Ed. 248, Art. 1641, Suplemento 1, 2013.

laboratorial se mostra de grande valia para a detecção de pacientes positivos 12 .

Devido ao emprego de diferentes técnicas e a dificuldade de se estabelecer quais delas são as mais propicias para se fechar o diagnóstico de LVC, sem a ocorrência de resultados falsos, este trabalho tem como objetivo avaliar os diferentes métodos de diagnóstico e concluir quais deles ou qual a associação entre eles é mais adequada para esta finalidade.

\section{REVISÃO DE LITERATURA}

Diferentes métodos podem ser utilizados para o diagnóstico da LVC. Muitos avanços têm ocorrido nos últimos anos, mas a despeito do grande número de testes disponíveis para o diagnóstico da doença, nenhum apresenta $100 \%$ de sensibilidade e especificidade. Por esta razão, recomenda-se a associação entre os vários métodos disponíveis, sendo pelo menos um parasitológico ${ }^{11,13}$. Entre os diferentes métodos de diagnóstico para LVC, podem ser utilizados a avaliação clínica, testes bioquímicos, sorológicos, parasitológicos, imunológicos e moleculares ${ }^{9}$.

\section{- Avaliação clínica}

O diagnóstico clínico da LVC é dificultado devido à variedade de sintomas que também são comuns a outras patologias, como brucelose, toxoplasmose e babesiose ${ }^{9}$. Além disso, outro fator complicante é o de que os cães infectados podem se apresentar na forma assintomática, sintomática ou oligossintomática 16.

Os sinais clínicos comumente observados nos animais infectados são linfoadenomegalia, hiporexia, onicogrifose, emagrecimento progressivo, alterações hepáticas, alterações renais, lesões ulcerativas na região nasal, atrofia da musculatura, alopecia, lesões de ponta de orelha, lesões perioculares, descamações cutâneas, dermatose ulcerativa, coagulopatias, icterícia e anemia ${ }^{16}$. 
LIMA, C.A. et al. Diagnóstico da leishmaniose visceral canina: uma revisão. PUBVET, Londrina, V. 7, N. 25, Ed. 248, Art. 1641, Suplemento 1, 2013.

- Testes bioquímicos

De forma associada à avaliação clínica, podem ser realizados também alguns exames complementares, como hemograma, avaliação da função renal, hepática, dosagem de eletrólitos e fração albumina/globulina. Os achados laboratoriais caracterizam-se principalmente por alterações hematológicas (como a anemia, geralmente normocítica normocrômica), hiperglobulinemia, hipoalbuminemia, hiperproteinemia, trombocitopenia, leucopenia associada à linfopenia ou leucocitose Podem ser realizados também exames radiográficos e ultrassonográficos, que permitem identificar lesões e alterações decorrentes da LVC $^{13,16 .}$.

É importante ressaltar que estes exames podem ser úteis para acompanhar os estágios clínicos da doença ${ }^{8}$, entretanto, as alterações que podem ser encontradas nas provas bioquímicas são inespecíficas, tornando necessário o uso de outros testes para a confirmação da suspeita ${ }^{10}$.

- Testes sorológicos

Na LVC há grande produção de anticorpos devido à intensa estimulação policlonal de linfócitos B causada pela doença. Assim sendo, o diagnóstico realizado através de provas sorológicas é facilitado, sendo que os métodos parasitológicos, que são invasivos, podem ser evitados ${ }^{6}$.

O material utilizado pelos laboratórios para a realização dos exames sorológicos é o soro. Para obtê-lo, é necessário coletar o sangue, depositá-lo em um tubo sem anticoagulante e enviá-lo na forma refrigerada para o laboratório, onde o material será processado. É de suma importância que a coleta do sangue seja realizada pelo médico veterinário, pois a correta coleta do material e a identificação dos tubos são de grande responsabilidade ${ }^{9}$.

Uma vez que existem dificuldades para a demonstração direta do parasito e pelo fato de existirem muitos pacientes assintomáticos, os métodos sorológicos tem sido muito utilizados para o diagnóstico da LVC ${ }^{14}$, inclusive em campanhas de inquéritos epidemiológicos ${ }^{9}$. Atualmente, em municípios onde já houve registro da doença, são utilizados na rotina e nos inquéritos caninos o 
LIMA, C.A. et al. Diagnóstico da leishmaniose visceral canina: uma revisão. PUBVET, Londrina, V. 7, N. 25, Ed. 248, Art. 1641, Suplemento 1, 2013.

Ensaio Imunoenzimático (ELISA), como método de triagem, e a Reação de Imunofluorescência Indireta (RIFI) como confirmatório ${ }^{4}$.

Estudos realizados em 2007 analisaram esses testes em quatro laboratórios distintos, demonstrando para o RIFI sensibilidade de $98,8 \%$ e especificidade de $94,7 \%$ e para o ELISA sensibilidade de $98 \%$ e especificidade de $96,5 \%$ (no mínimo) ${ }^{4}$.

É importante ressaltar que caso o resultado seja positivo, deve-se fazer a contraprova com o exame parasitológico, devido à possibilidade de reações cruzadas oriundas de anticorpos produzidos por outras infecções, que podem ser causadas por Erhlichia sp, Babesia sp, Neospora sp, Trypanossoma cruzi, $T$. caninum e outras espécies causadoras de leishmaniose tegumentar ${ }^{12,14}$.

Atualmente, o desempenho dos métodos sorológicos utilizados são limitados pelos antígenos empregados, os quais são derivados, na maioria das vezes, de promastigotas de cultura, parasitas íntegros ou moléculas solúveis, o que interfere na expressão da especificidade do teste, não alcançando assim o valor de $100 \%{ }^{1,18}$. Desta forma podem ocorrer reações cruzadas com outras espécies da família Trypanosomatidae e até mesmo com microorganismos filogeneticamente distantes ${ }^{18}$. A identificação de antígenos recombinantes ou purificados, como as glicoproteínas de membranas gp63, gp72, gp70 e rK39 específicas do gênero Leishmania, tem contribuído para melhorar a sensibilidade e a especificidade destes métodos, uma vez que os mesmos se caracterizam por induzir a formação de anticorpos específicos detectáveis nos testes sorológicos ${ }^{1}$.

O mais potente e promissor antígeno sorológico que tem sido utilizado é o recombinante rK39 ${ }^{1,3}$. Esta proteína apresenta seqüência idêntica em sete espécies de Leishmania, sendo que a conservação de uma seqüência de 39 aminoácidos the confere epítopos de alta densidade e identidade especifica com as espécies de $L$. donovani, $L$. infantum e $L$. chagasi. Este antígeno não apresentou reatividade com outros tripanossomatídeos e por isso a presença de anticorpos anti- rK39 indicaria a infecção ativa ${ }^{3}$. Devido à estes aspectos, foram desenvolvidos testes sorológicos rápidos, baratos e de fácil execução, 
LIMA, C.A. et al. Diagnóstico da leishmaniose visceral canina: uma revisão. PUBVET, Londrina, V. 7, N. 25, Ed. 248, Art. 1641, Suplemento 1, 2013.

baseados na detecção de anticorpos contra o antígeno rK39, como o Kalazar Detect ${ }^{\circledR}$. Estudos realizados tanto com cães quanto com humanos, demonstraram que a sensibilidade deste teste varia entre 82 a $100 \%$, já a especificidade varia de 95 a $100 \%$, dependendo da região estudada ${ }^{17}$.

A técnica de Western blot (WB) um método em biologia molecular que detecta proteínas, sendo descrita como a mais sensível e específica para detecção da infecção canina, tendo desempenho superior ao ELISA ou RIFI ${ }^{19}$.

Em 2006, um estudo com infeç̧ão experimental em cães revelou que o WB foi capaz de discriminar animais na fase de infecção recente ou tardia. Bandas imunodominantes foram detectadas, indicando inclusive, o prognóstico negativo para animais cujo parasitismo persistiu após o tratamento. Isso sugere que essa técnica pode ser usada como preditora da infecção e do parasitismo no cão ${ }^{19}$. Além disso, um outro estudo realizado em 2005 confirmou maior sensibilidade do teste quando comparado à RIFI, visto que, no estudo, $26 \%$ dos cães que estavam negativos para a RIFI já reconheciam as frações antigênicas até 8 meses antes da soroconversão. O estudo sugere que, provavelmente, cães positivos para WB e negativos para RIFI sejam animais resistentes que apresentam baixos níveis de anticorpos não detectáveis na RIFI ${ }^{15}$.

\section{- Parasitológico}

A visualização de formas amastigotas de Leishmania, pela análise microscópica de aspirado de linfonodos, medula óssea ou baço é o teste confirmatório para a LV. Apesar da especificidade ser elevada, a sensibilidade pode variar, sendo de 93 a $99 \%$ para o baço, 53 a $86 \%$ para a medula óssea e 53 a $65 \%$ para os linfonodos ${ }^{2}$.

A sensibilidade destes testes pode variar também de acordo com o grau de parasitismo do animal, o tipo de material biológico coletado para o exame, o tempo entre a coleta do material e a leitura da lâmina e da experiência e tempo despendido para o exame pelo profissional que irá ler a lâmina. Além disso, o uso de esfregaços de sangue periféricos não é recomendado por 
LIMA, C.A. et al. Diagnóstico da leishmaniose visceral canina: uma revisão. PUBVET, Londrina, V. 7, N. 25, Ed. 248, Art. 1641, Suplemento 1, 2013.

apresentarem baixa sensibilidade. O diagnóstico falso positivo só ocorrerá caso a forma amastigota da Leishmania seja confundida com alguma outra célula contida no esfregaço ${ }^{2}$.

Outro método parasitológico é o teste imunohistoquímico, o qual é realizado a partir de fragmentos de tecidos retirados de biópsias, principalmente da face interna do pavilhão auricular de cães, onde são encontradas maiores concentrações do parasito ou com conteúdo obtido da punção de linfonodos ou medula óssea. Esse teste possui de $70 \%$ a $80 \%$ de sensibilidade e $100 \%$ de especificidade ${ }^{1}$.

O mecanismo básico do teste é o reconhecimento do antígeno de Leishmania spp pela utilização de um anticorpo (Ac primário), que irá se associar ao antígeno. Posteriormente um segundo anticorpo irá se ligar ao primeiro (AC primário), dando origem a uma fluorescência, que permite então visualizar o antígeno que estará fluorescente. Este teste avalia o potencial de transmissão do animal ${ }^{9}$.

\section{- Cultivo Parasitológico}

No cultivo parasitológico, formas amastigotas do parasito inoculadas em meios de cultura especiais contendo agar e sangue de coelho, transformam-se em promastigotas e seu crescimento leva de três a cinco dias. Esses meios de diagnóstico têm baixa sensibilidade, especialmente nos estágios iniciais da doença, nos quais a carga parasitária é pequena ${ }^{5,9}$. Neste método utiliza-se sangue colhido da medula óssea e resultado pode demorar até 60 dias para ficar pronto ${ }^{5}$.

\section{- Reação em cadeia polimerase (PCR)}

A forma mais utilizada no diagnóstico molecular é a Reação em Cadeia de Polimerase (PCR), que permite identificar e ampliar seletivamente seqüências de DNA do parasito. O mesmo pode ser detectado em vários tecidos, como medula óssea, pele, aspirados de linfonodos, sangue e cortes histológicos de 
LIMA, C.A. et al. Diagnóstico da leishmaniose visceral canina: uma revisão. PUBVET, Londrina, V. 7, N. 25, Ed. 248, Art. 1641, Suplemento 1, 2013.

tecidos parafinados. Embora esse teste possa ser feito com sangue, não se recomenda a utilização deste por apresentar baixa sensibilidade ${ }^{5}$.

O PCR possui entre $38 \%$ e $76 \%$ de sensibilidade e $100 \%$ de especificidade. Embora identifique o DNA do parasito e o prévio contato do animal com este, não confirma a presença do parasito viável ou doença. Assim sendo, um único resultado negativo de PCR de um animal suspeito não é suficiente para descartar a infecção, uma vez que dependendo da carga parasitária do animal, o DNA do parasito não será encontrado, ocorrendo, portanto, falso negativo ${ }^{11}$. Possíveis resultados falso-positivos também merecem atenção, pois, dados da literatura indicam que as abordagens direcionadas para a amplificação de regiões do kDNA de Leishmania são as que apresentam maior sensibilidade, além disso, a acurácia dos resultados dependerá também da consciência do profissional que irá realizar o exame com relação aos fatores de risco que geram contaminações ${ }^{7}$.

- Outros testes

O teste de aglutinação direta (DAT) foi desenvolvido, inicialmente, para o diagnóstico da leishmaniose humana, mas tem sido usado em caráter experimental em cães. Este teste demonstrou ser igualmente sensível e específico como o ELISA A grande vantagem desse teste está na sua simplicidade e baixo custo quando comparado a outros. Sua execução é simples e o teste é quantitativo, porém, requer longo período de incubação (18 horas), o que pode ser um fator limitante do seu uso ${ }^{11,12}$.

Outro teste, muito semelhante ao DAT, é o fast agglutination-screening test, também chamado de teste de aglutinação rápida (FAST), cujo período de incubação é curto ( 3 horas). O FAST é apenas qualitativo e seu desempenho, associado à facilidade de execução, o torna um bom candidato como teste de triagem da doença ${ }^{9}$. 
LIMA, C.A. et al. Diagnóstico da leishmaniose visceral canina: uma revisão. PUBVET, Londrina, V. 7, N. 25, Ed. 248, Art. 1641, Suplemento 1, 2013.

\section{DISCUSSÃO}

A LV vem apresentando clara tendência de expansão geográfica nas últimas décadas. Alguns fatores como rápido crescimento das cidades, agravado pela falta de planejamento urbano, impactos ambientais, fenômenos climáticos, implantação de projetos agroindustriais, e progressiva deteriorização da condição socioeconômica de ampla parcela das populações urbanas têm sido citados como responsáveis pela expansão e reemergência da doença em vários países ${ }^{11,13}$.

Diagnosticar clinicamente a LVC é problema para as autoridades de saúde, uma vez que não existem sinais clínicos específicos da doença. Desta forma, os animais podem se apresentar aparentemente sadios, com poucos sintomas ou com sintomatologia grave. A LVC pode ficar também clinicamente inaparente por anos, dependendo da sua fase e do estado imunológico do animal. Nesta situação, o cão pode se constituir fonte de infecção para os insetos vetores, pois, mesmo aparentemente sadio, pode conter formas do parasito na pele ${ }^{12}$.

Devido à dificuldade de diagnóstico da doença através da sintomatologia clínica, é de suma importância que o profissional da área esteja atualizado quanto aos métodos de diagnóstico disponíveis. Estes métodos, por sua vez, devem ser capazes de identificar os indivíduos infectados de maneira segura e confiável. Além disso, para serem utilizados em grande escala, o ideal é que as provas também tenham como características fácil execução e baixo custo ${ }^{12,13}$. Em relação aos testes sorológicos, mesmo existindo um teste extremamente eficiente, um percentual dos casos positivos ainda permaneceriam indetectáveis, especialmente em animais que estejam no período de incubação do parasito ou então em período de soroconversão, uma vez que durante essas fases, os níveis de anticorpos podem sofrer grandes variações, gerando resultados sorológicos imprevisíveis. Além disso, outro problema são os casos falso positivos, que podem ocorrer, por exemplo, devido a reações cruzadas ${ }^{1}$. Desta forma, altos índices de sensibilidade e especificidade são necessários para evitar resultados tanto falso negativos, os quais subestimam as taxas de 
LIMA, C.A. et al. Diagnóstico da leishmaniose visceral canina: uma revisão. PUBVET, Londrina, V. 7, N. 25, Ed. 248, Art. 1641, Suplemento 1, 2013.

infecção na população de cães de áreas endêmicas, quanto reações falso positivas, as quais podem levar à eutanásia de cães não infectados ${ }^{11}$.

Para exemplificar, durante o período de 1993 a 1997, foram realizadas pesquisas sorológicas para a detecção de animais positivos, como parte de ações do programa de controle desenvolvido pela prefeitura de Belo Horizonte. $\mathrm{Na}$ ocasião, foram examinados 415.683 , sendo que 15.117 foram identificados como positivos e 400.566 foram diagnosticados como negativos. Considerando a prevalência verificada no período acima $(3,64 \%)$, os valores preditivos positivos e negativos da RIFI são, respectivamente, $14,5 \%$ e $99,5 \%$. Verificamos que dos 400.566 animais diagnosticados como negativos, 2.003 seriam, na verdade, falsos negativos, já dentre os 15.117 positivos, 12.925 seriam falsos positivos. Nesse contexto, podemos afirmar que existe uma elevada confiança no resultado deste exame, sendo que o mesmo pode não ser condizente com a realidade. Com implicações práticas nas atividades de controle de LVC na capital mineira, o programa sacrificou 12.924 animais falsos positivos e deixou de sacrificar 2.003 animais falsos negativos ${ }^{1}$.

Uma das formas de minimizar as deficiências encontradas pelos testes sorológicos, é através da busca de novos antígenos, que permitam a detecção de anticorpos IgG tanto na fase sintomática quanto na assintomática, possibilitando melhor sensibilidade e especificidade para o teste. O rK39 se mostrou um ótimo candidato para isso, já que se revelou estável em áreas epidemiologicamente distintas detectando não só cães sintomáticos como também assintomáticos. Alguns estudos apontam os testes rápidos imunocromatográficos baseados no recombinante rK39 como a técnica ideal para as atividades no campo, pois tem se mostrado sensível, específico, rápido, barato e de simples utilização. No entanto, outros estudos discordam disso, pois a necessidade de se estocar o tampão de corrida em baixas temperaturas, as fitas reativas não poderem ser estocadas em temperaturas ambientais elevadas e a impossibilidade de se utilizar sangue total, limita o uso deste método ${ }^{1}$. 
LIMA, C.A. et al. Diagnóstico da leishmaniose visceral canina: uma revisão. PUBVET, Londrina, V. 7, N. 25, Ed. 248, Art. 1641, Suplemento 1, 2013.

Atualmente, nas campanhas de controles da LVC, o sorodiagnóstico parece ser a escolha mais apropriada e prática para ser utilizada. O MS estabelece oficialmente que um animal é considerado reagente quando apresenta titulação igual ou superior a 1:40 sendo, portanto, passível de eutanásia. Entretanto, a literatura científica mundial estabelece que apenas títulos iguais ou superiores a 1:160 sejam confirmatórios e 1:80 sejam suspeitos, necessitando de confirmação por outras metodologias ${ }^{13}$.

Cabe ressaltar que houve uma melhora significativa na qualidade do diagnóstico laboratorial da LVC realizado na rede pública nos últimos anos, devido a um aprimoramento das ferramentas utilizadas pelo Ministério da Saúde (MS) ${ }^{4}$.

Os lotes de ELISA e RIFI disponibilizados ao Ministério da Saúde têm passado por um rigoroso controle de qualidade, sendo que avaliações realizadas pela Funed/MG demonstram que todos os lotes de ELISA utilizados em rede pública em 2011 tiveram sensibilidade acima de 95\% e especificidade de 100\%, já o RIFI apresentou sensibilidade média acima de $98,3 \%$ e a especificidade superior a $94,1 \%{ }^{4}$.

Outro ponto importante que vem sendo adotado é o da não liberação de lotes com sensibilidade ou especificidade inferior a $90 \%$ para o uso em saúde pública. Esse protocolo de controle de qualidade adotado assegura a confiança no diagnóstico laboratorial da rede pública quando comparado à rede privada, em que não há um controle de qualidade externo dos lotes utilizados ${ }^{4}$.

Na atualidade, o Programa de Vigilância e Controle da Leishmaniose Visceral utiliza o ELISA como teste de triagem e a RIFI como teste confirmatório. Entretanto, em novas avaliações, o cenário que utilizou o teste rápido imunocromatográfico como triagem e o ELISA como confirmatório demonstrou melhor acurácia que os demais ${ }^{4}$.

O teste de imunocromatografia foi desenvolvido para o diagnóstico da LV humana, e vem sendo aplicado em estudos para a LVC ${ }^{12}$. O teste foi desenvolvido utilizando-se o rK39 fixado em papel (Teste Rápido Anticorpo Leishmania donovani - TRALd) e baseia-se na reação com o sangue, 
LIMA, C.A. et al. Diagnóstico da leishmaniose visceral canina: uma revisão. PUBVET, Londrina, V. 7, N. 25, Ed. 248, Art. 1641, Suplemento 1, 2013.

soro ou plasma do paciente. O mesmo é simples, rápido (cerca de 10 minutos) e prático, podendo ser realizado a partir de uma pequena amostra coletada ${ }^{11}$. Outras vantagens são a desnecessidade de equipamentos laboratoriais específicos, armazenamento sob refrigeração e especialização tecnológica ${ }^{4}$.

No Brasil, quando aplicado em cães de área endêmica, a sensibilidade foi de $92 \%$ e a especificidade de $99,5 \%$, entretanto, o teste não foi capaz de detectar infecção nos animais com títulos de RIFI baixos (1:40 a 1:320). Recentemente, o teste foi modificado, sendo acrescido do antígeno recombinante rK26 do complexo $L$. donovani, que também reconhece anticorpos específicos para espécies deste complexo. Na avaliação do novo TRALd, foi observado que indivíduos assintomáticos negativos ao rK39 mostraram-se positivos com o rk26, concluindo-se que a sensibilidade do teste foi ampliada ${ }^{11}$.

Esse novo protocolo recomendando pelo Ministério da Saúde, utilizando o teste rápido imunocromatográfico como triagem e o ELISA como confirmatório, deverá ser implantado gradativamente, à medida que o fornecimento do insumo produza um estoque suficiente para tal. Espera-se que, até o final de 2012, todos os Estados brasileiros estejam adotando o novo protocolo ${ }^{4}$.

Como complemento às provas sorológicas, os testes parasitológicos tem sido de grande valia na conclusão do diagnóstico da LVC, uma vez que o método possibilita a visualização do agente causador da doença. A técnica do aspirado de baço é inviável para ser utilizada na rotina por ser um procedimento de risco, diferente do aspirado de linfonodo e medula óssea. Entretanto, apesar de não apresentar tanto risco, as duas últimas são técnicas que possuem menor sensibilidade ${ }^{11}$.

Outra técnica importante para o diagnóstico da LVC é a PCR. Apesar da alta especificidade, as técnicas moleculares possuem a desvantagem de requerer laboratórios bem equipados. Desta forma, o método acaba sendo menos usado em diagnósticos de rotina, uma vez que para ser empregada em larga escala, a PCR necessita de ajustes para se tornar mais simples e com custo operacional mais baixo ${ }^{1}$. Muitos estudos ainda encontram-se na fase de 
LIMA, C.A. et al. Diagnóstico da leishmaniose visceral canina: uma revisão. PUBVET, Londrina, V. 7, N. 25, Ed. 248, Art. 1641, Suplemento 1, 2013.

pesquisa e esperam avaliações futuras em estudos epidemiológicos para poderem ser aplicados como ferramenta auxiliar ao diagnóstico clínico ${ }^{7}$. Já a utilização do cultivo parasitológico como método isolado para a conclusão do diagnóstico se mostra inviável devido ao longo prazo para a liberação do resultado, além de ser um teste que possui baixa sensibilidade ${ }^{4}$.

\section{CONCLUSÃO}

Atualmente, a LVC constitui grave problema de saúde pública e representa desafio para os profissionais da saúde. O estudo epidemiológico é fator decisivo para o planejamento efetivo de estratégias para o controle da doença, sendo que este controle exige ação sistemática e simultânea nos diversos elos da cadeia epidemiológica: esclarecimentos sobre a transmissão, prevenção e os cuidados devem ser informados para a população humana.

Por se tratar de doença complexa, é necessário que sejam feitas associações entre várias técnicas de diagnóstico, uma vez que nenhuma delas é $100 \%$ sensível e 100\% especifica. Assim sendo, o diagnóstico deve ser baseado na conjunção dos sinais clínicos (embora não sejam patognomônicos da doença), dados epidemiológicos, anamnese, exames laboratoriais e exames complementares. É importante ressaltar que somente o médico veterinário é apto para concluir o diagnóstico dessa doença em cães.

Atualmente, o método oficial utilizado para diagnóstico da LVC é o ELISA como teste de triagem e o RIFI como teste confirmatório. Com base em suas características, pode-se afirmar que estes testes realizados isoladamente não são confiáveis, desta forma, é recomendado que os mesmos sejam combinados a técnicas de pesquisa direta do agente através de exame parasitológico, associação esta que confere maior confiabilidade ao diagnóstico.

Mais recentemente, o MS divulgou nota esclarecendo sobre um novo protocolo para inquéritos caninos, baseado na utilização da imunocromatografia como teste de triagem e o ELISA como teste confirmatório. O mesmo apresenta as 
LIMA, C.A. et al. Diagnóstico da leishmaniose visceral canina: uma revisão. PUBVET, Londrina, V. 7, N. 25, Ed. 248, Art. 1641, Suplemento 1, 2013.

vantagens de possuir coleta simples e fácil armazenamento, além de poder ser usado em larga escala. Desta forma, apesar de algumas limitações, o teste parece ser promissor para uso em programas de saúde pública.

\section{Referências bibliográficas}

1. ALVES, W. A; BEVILACQUA, P. D. Reflexões sobre a qualidade do diagnóstico da leishmaniose visceral canina em inquéritos epidemiológicos: o caso da epidemia de Belo Horizonte, Minas Gerais, Brasil, 1993 - 1997. Cad. de Saúde Pública, v.20, n.1, p.259-265, jan/fev. 2004.

2. BABIKER, Z.O., DAVIDSON, R., MAZINDA, C., KIPNGETICH, S., RITMEIJER, K. Utility of lymph node aspiration in the diagnosis of visceral leishmaniasis in Sudan. The American Journal of Tropical Medicine and Hygiene, n.76, p.689-693. 2007.

3. BISUGO, M.C., ARAÚJO, M.F., TANIGUCHI, H.H., ACUNHA, E., SANTOS, A.A., JUNIOR, M.S., KANETO, C.N., CAMARGO, C.V.O., POLIZEL, M.A., VIGILATO, M.A.N., NEGREIROS, C.M.S., OKAGIMA, M., GONÇALVES, N.M., LUNDSTEDT, L.P., ANDRADE, A.M., LIMA, V.M.F., TOLEZANO, J.E. Avaliação do diagnóstico da leishmaniose visceral canina com a utilização de teste rápido com antígeno recombinante K39 em regiões endêmicas do estado de São Paulo. Revista do Instituto Adolfo Lutz, n.66, p.185-193. 2007.

4. BRASIL. Ministério da Saúde. Esclarecimentos sobre o diagnóstico sorológico da leishmaniose visceral canina utilizado na rede pública de saúde. Brasília. p.1-5. 2011.

5. BRASIL. Ministério da Saúde. Manual de vigilância e controle da leishmaniose visceral. Brasília, p.120, 2003.

6. CORTÉS, A.R., OJEDA, A., FUERTES, L.L., TIMÓN, M., ALTET, L., GALLEGO, L.S., ROBERT, E.S., FRANCINO, O., ALBEROLA, J. A long term experimental study of canine visceral leishmaniasis. International Journal for Parasitology, n.37, p.683-693. 2007.

7. CUPOLILLO, E. Avanços dos Estudos Moleculares de Leishmania (Leishmania) Chagasi Aplicados ao Diagnóstico de LV no Brasil. In: Consulta De Expertos Ops/Oms Sobre Leishmaniasis Visceral En Las Américas, 2005, Brasília. Anais... Brasília: Ministério da Saúde do Brasil, 2006. p.57-62.

8. DIAS, E.L.; BATISTA, Z.S.; GUERRA, R.M.S.N.C; CALABRESE, K.S.; LIMA, T.B.; SILVA, A.L.A. Canine Visceral Leishmaniasis (CVI): Seroprevalence,Clinical, Hematological And Biochemical Findings Of Dogsnaturally Infected In An Endemic Area Of São José De Ribamarmunicipality, Maranhão State, Brazil. Ciência Animal Brasileira, v. 9, n. 3, p. 740745, jul./set. 2008.

9. DOTTA, S.C.N.; LOT, R.F.E.; ZAPPA, V. Métodos de diagnóstico da leishmaniose visceral canina. Revista Científica Eletrônica De Medicina Veterinária, n.12. jan. 2009.

10. FEITOSA, M. M. Avaliação clínica de animais naturalmente infectados. I Forum sobre leishmaniose visceral canina, anais, Jaboticabal, 10 e 11 de março de 2006.

11. GONTIJO, C. M. F; MELO, M. N. Leishmaniose visceral no Brasil: quadro atual, desafios e perspectivas. Revista Brasileira de Epidemiologia, São Paulo, v.7, n.3, set. 2004.

12. LEAL, C. R. B. Métodos disponíveis e possíveis para o diagnóstico da leishmaniose visceral americana canina. In: II Fórum de Discussão da Sociedade Paulista de Parasitologia: Leishmaniose visceral americana, situação atual e perspectivas futuras, 2007, São Paulo. Anais... São Paulo, 2007. 
13. NOGUEIRA, J.L.; SILVA, M.V.M.; PASSOS, C.C.; AMBRÓSIO, C.E. A Importância Da Leishmaniose Visceral Canina Para A Saúde Pública: Uma Zoonose Reemergente. Revista Científica Eletrônica De Medicina Veterinária, n.13, jul. 2009.

14. ROSÁRIO, E.Y., GENARO, O., SILVA, J.C.F., COSTA, R.T., MAYRINK, W., REIS, A.B., CARNEIRO, M. Evaluation of enzyme-linked immunosorbent assay using crude Leishmania and recombinant antigens as a diagnostic marker for canine visceral leishmaniasis. Memórias do Instituto Oswaldo Cruz, n.100, p.197-203. 2005.

15. SILVA, A V. M.; PAULA, A. A. de; CABRERA, M. A. A.; CARREIRA, J. C. A. Leishmaniose em cães domésticos: aspectos epidemiológicos. Cadernos de Saúde Publica, v.21, n.1, 2005.

16. SILVA, F. S. Patologia e patogênese da leishmaniose visceral canina. Revista Tropical - Ciências Agrárias e Biológicas, v.1, n.1, p.20, 2007.

17. SUNDAR, S., MAURYA, R., SINGH, R.K., BHARTI, K., CHAKRAVARTY, J., PAREKH, A., RAI, M., KUMAR, K., MURRAY, H.W. Rapid, Noninvasive Diagnosis of visceral leishmaniasis in India: comparison of immunochromatographic strip tests for detection of anti-k39 antibody. Journal of Clinical Microbiology, n.44, p.251-253. 2006.

18. SUNDAR, S., RAI, M. Laboratory diagnosis of visceral leishmaniasis. Clinical and Diagnostic Laboratory Immunology, n.9, p.951-958. 2002.

19. TALMI-FRANK, D; STRAUSS-AYALI, D; JAFFE, CL; BANETH, G. Kinetics and diagnostic and prognostic potential of quantitative Western blot analysis and antigen-specific enzymelinked immunosorbent assay in experimental canine leishmaniasis. Clinical Vaccine Immunology, v.13, n.2, p.271-276, 2006. 